\title{
Associação dos Escoteiros do Alecrim: uma "escola de disciplina e ordem" para a juventude natalense
}

Iranilson Buriti de Oliveira Universidade Federal de Campina Grande Andressa Barbosa de Farias Leandro Universidade Federal da Paraíba

\section{Resumo}

O presente trabalho analisa as práticas educativas escoteiras da Associação de Escoteiros do Alecrim (A.E.A), situada na cidade de Natal-Rio Grande do Norte, entre os anos de 1937-1945, dialogando com os ideais político-pedagógicos do Estado Novo. O trabalho orientado pelas discussões teóricas sobre o poder e as artes disciplinares, discutidas por Michel Foucault (1 987), e de cultura escolar, propostas por Julia (2001), articulado ao diálogo com fontes escritas e iconográficas, constatou que, nesse recorte temporal, as autoridades políticas do Estado Novo se apropriaram da prática educativa escoteira, incorporando a União dos Escoteiros do Brasil (UEB) à Organização da Juventude Brasileira. A partir de então, a Associação de Escoteiros do Alecrim passou a educar e normatizar o comportamento da juventude natalense para adequá-lo aos moldes do regime vigente. Considerando que a Associação dos Escoteiros do Alecrim é parte da memória educacional do Estado do Rio Grande do Norte, pretendemos que este estudo venha contribuir com a historiografia da educação no Brasil e estimular o debate e a produção acadêmica sobre a prática escoteira em outros estados da federação.

Palavras-chave: Associação dos Escoteiros do Alecrim. Juventude. Estado Novo.

\section{Association of Alecrim Scout: a "discipline of school and order" for youth natalense}

\section{Abstract}

This study analyzes the educational scout practices of the Scout Association of Alecrim (A.E.A), located in Natal-RN, from 1937 to 1945, dialoguing with the political-pedagogical thoughts of the "Estado Novo"- New state. The work, guided by the theoretical discussions about power and the disciplinary arts, discussed by Michel Foucault (1987), and school culture, proposed by Julia (2001), articulated to the dialogue with written and iconographic sources, found that in this time cut, the political authorities of the New State seized the educational practice of Scouting, incorporating the Brazilian Scout Union (UEB) to the Brazilian Youth Organization. From then on, 
the Scout Association of Alecrim began to educate and regulate the behavior of the native youth to adapt it to the molds of the current regime. Considering that the Scout Association of Alecrim is part of the educational memory of the State of Rio Grande do Norte, we intend that this study will contribute to the historiography of education in Brazil and stimulate the debate and the academic production on scout practice in other states of the federation.

Keywords: Scout Association of Alecrim. Youth. New State.

\section{Asociación scouts do Alecrim Scouts: una "escuela de disciplina y ordem" para juventud natalense}

\section{Resumen}

Este artículo analiza las prácticas educativas de Asociación de Scouts de Alecrim (A.E.A), situada en la ciudad de Natal, Rio Grande do Norte, entre los años 1937-1945, dialogando con los ideales político-pedagógicos del Estado Novo. El trabajo, guiado por las discusiones teóricas sobre el poder y artes disciplinarias, discutido por Michel Foucault (1 987), y por la cultura escolar, propuesta por Julia (200 1), articulado com el diálogo con las fuentes escritas e iconográficas, encontró que en este período de tiempo, las autoridades políticas del Estado Novo apropiaron de la práctica educativa de la corporación scouts, incorporando la Unión de Scouts de Brasil (UEB) a la Organización Juvenil Brasileña. Desde entonces, la Asociación de Scouts de Alecrim comenzó a educar y regular el comportamiento de los jóvenes de Natal para adaptarlos y moldear al sistema existente. Mientras que la Asociación de Scouts de Alecrim es parte de la memoria educativa de Rio Grande do Norte, pretendemos que este estudio contribuya con la historia de la educación en Brasil y para estimular el debate y el estudio sobre la práctica Scout en otros estados.

Palabras clave: Associación de los Scouts de Alecrim. Juventud. Estado Novo.

\section{Introdução}

Apesar de ter sido implantado há mais de um século no Brasil, o escotismo ainda é uma temática pouco estudada pelos pesquisadores brasileiros. Conforme assinalou Nascimento (2008), os trabalhos sobre o tema são recentes e se restringem, sobretudo, aos Estados de São Paulo e Minas Gerais. Entretanto, assim como Thomé (2005), acreditamos que o escotismo se constitui em um tema relevante para a história da educação brasileira, haja vista que ele é caracterizado como um movimento de educação extraclasse, que se 
enquadra, historicamente, entre as organizações extraescolares destinadas à complementação da educação formal nos estabelecimentos de ensino, tem a sua parcela de contribuição à educação da infância e da juventude brasileira. Logo, o escotismo é parte integrante da memória educacional do país.

Não obstante, a carência de pesquisas sobre a temática escoteira evidencia, conforme assinalou Zuquim e Cytrynowicz (2002), que o escotismo, apesar de sua forte presença em muitas cidades brasileiras, tem sido menosprezado pela historiografia brasileira. Todavia, somente mediante os trabalhos acadêmicos, poderemos compreender a proposta, os elementos e o sentido dessa prática extraescolar que, durante mais de cem anos, vem servindo de complemento para educação de muitas crianças e jovens brasileiros.

Fundado no início do século XX (1907) pelo general inglês Lord Robert S. Smith Baden-Powell, o escotismo é implantado, no Brasil, a partir da cidade do Rio de Janeiro, em 1910, impulsionado por Olavo Bilac e Mário Cardin e organizado por suboficiais dos encouraçados "Minas Gerais" e "São Paulo", que haviam convivido com o movimento escoteiro na Inglaterra. Com o lema "CRIAR MOCIDADE FORTE E VALENTE PARA SER MAIS TARDE DIGNA DA PÁTRIA EM QUE NASCEU", o escotismo "invade" a Região Nordeste num momento em que esta necessitava de referenciais de masculinidade para a sua sociedade. Instalando-se na área urbana e concentrando-se, inicialmente, apenas nas capitais dos Estados, o escotismo ganhava nome, fama e honra, atingindo, também, outras cidades do interior, como Jaboatão dos Guararapes-Pernambuco, onde o escotismo foi introduzido pelo General Newton Cavalcanti, em 1936 (O ESCOTISMO, 1936).

Inicialmente pensado para complementar a educação de jovens ingleses, o escotismo rapidamente se propagou para outros países?'. Para Nascimento (2004), o grande sucesso e a rápida difusão alcançada pelo escotismo, no início do século XX, justificam-se pelo fato de o projeto de BadenPowell contribuir com um tipo de educação que produzia sujeitos integrados aos ideais nacionais, servindo de vetor de nacionalismo político para essas nações no período entre guerras, inclusive no Brasil.

No Brasil, o escotismo despertou o interesse das autoridades políticas brasileiras, estabelecimentos de ensinos, igreja, entre outros e se expandiu para outros estados da federação, a exemplo do Rio Grande do Sul, Maranhão, Sergipe, Amazonas, Espírito Santo, Bahia, Paraná e Rio Grande do Norte, 
entre outros (BLOWER, 1994). Com a implantação e expansão do escotismo, as autoridades políticas brasileiras, dentre as quais Getúlio Vargas, desejavam ver em cada garoto um soldado, brigando contra as "forças do mal" (principalmente representadas pelo Comunismo). Livros didáticos, revistas (a exemplo da Sesinho), palestras, discursos diversos vão saturar a família burguesa com metáforas militares e nacionalistas.

Souza (2000) argumenta que, logo após a I Guerra Mundial (191419181, o Brasil vivencia uma onda de efervescente nacionalismo. Que rosto construir para o Brasil diante de tantas rostidades? A Europa parecia feia demais diante de tantos escombros deixados pela guerra! Que projeto político escrever para um país ainda agrícola e rural, mas com sede de urbanização e de industrialização? É nesse contexto republicano que os programas de governo surgem visando à "formação das almas" patriotas, conforme expressão de José Murilo de Carvalho. Surge uma série de movimentos e de campanhas de cunho nacionalista, desejosa de soerguer moral e politicamente o país. O voto secreto, a erradicação do analfabetismo, o serviço militar obrigatório, a igualdade de gênero eram reivindicações alimentadas pelo fervor nacional e pelos políticos e intelectuais descontentes com a atual estrutura de poder da jovem República. Somando-se a essas reivindicações, a questão da nacionalidade brasileira emerge com o combate à estrangeirização, às reformas políticas, à moralização dos costumes e à regeneração nacional (SOUZA, 2000).

Dessa forma, o escotismo espalhou-se e consolidou-se em vários estados e, para isso, teve amplo apoio dos Poderes Públicos. As pesquisas revelaram que esse apoio não ficou restrito ao momento da implantação do escotismo, mas também a outros momentos, ao longo desses cem anos, a exemplo do período do primeiro governo de Getúlio Dornelles Vargas (19301937). Instigados pela temática escoteira, voltamos nossos olhares para o percurso trilhado pelo Movimento Escoteiro na cidade do Natal-RN, durante o recorte cronológico do Estado Novo (1937-1945). A escolha da espacialidade deve-se ao fato de que a Associação dos Escoteiros do Alecrim (A.E.A), autoridade máxima do escotismo no Estado do Rio Grande do Norte, foi bastante atuante no que tange à educação da infância e da juventude potiguar nesse período. Assim, pretendemos analisar as aproximações entre a prática educativa escoteira vivenciada na cidade do Natal-RN e o projeto político pedagógico do Estado Novo. 
Concordamos com Nascimento (2008) quando este se apropria da interpretação de Julia (2001) e defende que o escotismo deve ser compreendido como "cultura escoteira" que se adequou a diferentes culturas infantis e juvenis. Assim, apesar de a Associação dos Escoteiros do Alecrim configurar uma instituição extraescolar de complemento educacional, destinada à infância e juventude natalenses, entendemos que as práticas escoteiras desenvolvidas na Associação se aproximam daquilo que Julia (2001) chamou de cultura escolar, uma vez que essas práticas constituíam um conjunto de normas que definiam valores e condutas que deveriam ser inculcadas e incorporadas pelos seus membros. Ademais, sabemos que o processo de implantação do escotismo nas cidades brasileiras não ocorreu de forma homogênea, mesmo porque se deu em temporalidades e contextos distintos.

A análise das notícias sobre a A.E.A, publicadas no jornal A República, no período de 1937 a 1945, nos ajudará a compreender o contexto e os discursos propagados sobre a prática escoteira no estado norte-rio-grandense e no Brasil. Partindo da premissa de que o jornal é um documento histórico e portador de um discurso, ele não pode ser analisado como algo que é isento de intencionalidades; por isso, Lucca (2008, p. 132) argumenta que "[... é

156 importante estar alerta para os aspectos que envolvem a materialidade dos impressos e seus suportes, que nada têm de natural".

Destarte, acreditamos que a "cultura escoteira" caracterizada nas práticas desenvolvidas na A.E.A durante o período do Estado Novo (1937-1945) se constitui em importante objeto da História da Educação visto que essas práticas estão imbuídas do discurso político, educacional e cívico, propagados na época. $O$ escotismo pode ser problematizado como modelo social de educação disciplinadora e coordenadora, baseado na modelização atlética do corpo e na obediência sem questionamentos às autoridades.

\section{A emergência do Escotismo na cidade do Natal}

"Venho lembrar e pedir a sua bela alma de brasileiro em grande serviço: a criação no Rio Grande do Norte de batalhões de escoteiros" (Escotismo no RN completa 90 anos. Jornal Tribuna do Norte, 05 de março de 2007). Atendendo a essa solicitação de Olavo Bilac, entusiasta do escotismo, Henrique Castriciano, então secretário de governo, se articula com seus 
amigos, o professor Luiz Correia Soares de Araújo e o comandante Antônio Monteiro Chaves, para implantar o escotismo no estado norte-rio-grandense:

Em 25 de março de 1917, o poeta Olavo Bilac, então secretário geral da Liga de Defesa Nacional, dirigiv expediente ao Dr. Henrique Castriciano, secretário do governo do Rio Grande do Norte, solicitando que despertasse na juventude e na imprensa o interesse pelo escotismo. Henrique Castriciano assumiu a incumbência e convidou o professor Luiz Soares e Monteiro Chaves, comandante da Escola de Aprendizes Marinheiro, e juntos fundaram $\circ 1^{\circ}$ Grupo de Escoteiros do Alecrim, em 24/06/1917 (ESCOTEIROS COMEMORAM 51 ANOS DE EXISTÊNCIA, 1970, p. 2).

Inicialmente, o Grupo de Escoteiros do Alecrim era composto por 32 jovens. Posteriormente, com o aumento do número de membros, distribuídos em três tropas escoteiras, duas alcateias, um ramo sênior e um clã pioneiro, o Grupo vai ser elevado à condição de associação, passando a se chamar, a partir de 14 de julho de 1919, Associação dos Escoteiros do Alecrim (A.E.A), cujo intuito era "[...] desenvolver entre a infância e juventude, a destreza e o vigor físico, o espírito de iniciativa, a decisão pronta, a coragem prudente e proveitosa, o civismo, o sentimento de solidariedade, de previdência, de responsabilidade moral e de honra, no interesse próprio e a bem da Pátria" (SOBRE O ESCOTISMO, 1937, p. 2.)

Os primeiros escoteiros eram jovens oriundos do Grupo Escolar Frei Miguelinho2, do qual o professor Luiz Soares Correia de Araújo era diretor ${ }^{3}$. Provavelmente, esses escoteiros eram garotos pobres, já que eles eram alunos desse Grupo Escolar, localizado no bairro do Alecrim e de acordo com Pinto e Morais (201 1, p. 5), "[...] geralmente, os alunos eram filhos de operários, pedreiros, agricultores, dentre outros".

As primeiras reuniões ocorreram na residência de Henrique Castriciano, posteriormente, passaram a ser realizadas na casa do comandante Monteiro Chaves até serem transferidas de forma definitiva para sede própria, no bairro do Alecrim. A sede foi construída, no ano de 1921, na gestão do governador Antônio José de Melo e Sousa ${ }^{4}$, com apoio do presidente da República Epitácio Pessoa ${ }^{5}$, em terreno doado pelo governador Joaquim Ferreira Chaves ${ }^{6}$, no ano de 1918. 
A doação do terreno, assim como a construção da sede, reforça a ideia de que, desde a sua implantação na cidade potiguar, o escotismo contava não só com o apoio das autoridades políticas locais, como também com o apoio do governo federal, que subvencionava a Associação dos Escoteiros do Alecrim7. A preocupação com a formação moral, física e cívica da juventude, nesse período, justifica esse apoio.

\section{A juventude, o Estado-Novo e a Construção do Sentimento de Civismo}

Inicialmente, a juventude foi vista como uma possível ameaça ao regime autoritário de Vargas; desse modo, era preciso educar "[...] a juventude em relação ao sentimento de civismo e depurar costumes sociais que pudessem interferir na construção de uma nova identidade nacional" (ARAÚjO, 2000, p. 34). Uma juventude saudável e disciplinada, capaz de demonstrar sua obrigação cívica, era fundamental para a prosperidade da nação, associada, nesse período, ao Estado Novo.

Nesse contexto, a juventude e a infância brasileira ocupavam um lugar de relevo nos debates da arena política e nos projetos educacionais. As escolas foram estrategicamente utilizadas para disseminar a ideologia do regime vigente, entretanto, conforme afirma Teixeira (201 1 , p. 169), "[...] era preciso que o Estado também dirigisse o comportamento das crianças fora da escola, nas suas atividades de lazer. Para isso deveriam ser promovidos jogos, atividades de escotismo e colônias de férias". Logo a Constituição de 1937 determinava que caberia ao estado criar instituições para promover a disciplina moral e o adestramento físico da juventude para que, assim, ela pudesse tornar-se "saudável" e apta a cumprir seus deveres junto à nação:

Estado fundará instituições ou dará o seu auxilio e proteção às fundadas por associações civis, tendo umas; e outras por fim organizar para a juventude períodos de trabalho anual nos campos e oficinas, assim como promover-the a disciplina moral e o adestramento físico, de maneira a prepará-la ao cumprimento de seus deveres para com a economia e a defesa da nação (ART. 132 DA CONSTITUIÇÃO DOS ESTADOS UNIDOS DO BRASIL, 1937, p. 33). 
Com o objetivo de organizar a juventude brasileira, o Ministro da Justiça, Francisco Luís da Silva Campos, elabora um projeto no qual propõe a criação da Organização Nacional da Juventude, uma instituição de âmbito nacional e de caráter paramilitar. Segundo Horta (2012, p. 198), em janeiro de 1938, o projeto é encaminhado para o presidente Getúlio Vargas, que o submeterá à apreciação do general Eurico Dutra e de Gustavo Capanema, respectivamente Ministro da Guerra e Ministro da Educação, cujos pareceres foram determinantes para o arquivamento do projeto. Entretanto, apesar do arquivamento, foi fortalecida "a ideia de criar no Brasil um movimento que se encarregasse da educação física, moral e cívica da juventude, inculcando-the a disciplina e servindo como instrumento de sua mobilização em torno da ideologia do Estado Novo".

De acordo com Dayrel (2003), a juventude é uma categoria social; por isso, se torna, ao mesmo tempo, "[...] uma representação sociocultural e uma situação social". Nesse sentido, os grupos juvenis institucionalizados, aqueles organizados por adultos, tais como: escolas, orfanatos, juventudes de igrejas, escotismo, entre outros, exercem uma importante tarefa: preparar o indivíduo para o mundo social, haja vista, que criam uma "realidade" social em que indivíduos da mesma idade ou idades semelhantes passam a conviver (GROPPO, 2004).

Parada (2009, p. 51 ) argumenta que, no contexto do estado Novo, a juventude era vislumbrada como recurso político, "[...] um investimento para a eliminação das tendências revolucionárias e não nacionalistas que habitavam o cenário políitico brasileiro, ainda pós 1937 [...]", por isso, Getúlio Vargas creditava aos jovens a missão de consolidar o novo regime:

Na mocidade que sacode os braços para o alto, como se pretendesse abraçar o sol e traz os olhos abertos pelo deslumbramento da vida que recém desponta, deposito minha confiança e a ela dirijo meu apelo, porque é uma força capaz de consolidar o Estado Novo (O PAPEL DA JUVENTUDE NO ESTADO NOVO, 1938, p. 10).

Assim, em novembro de 1938, Getúlio Vargas exclui o ministro da justiça do debate sobre a criação de uma organização da juventude, passando essa questão para Gustavo Capanema Filho, então ministro da Educação e Saúde (1934-1945). Após sucessivas reformulações, o projeto chegou a 
sua versão final, esvaziado do seu caráter paramilitar, configurando, apenas, um movimento de caráter cívico, voltado para o culto dos símbolos nacionais (HORTA, 2012).

Conforme Parada (2009, p. 109), ocorre, em 8 de março 1940, a institucionalização da Organização da Juventude Brasileira, pelo Decreto $n^{0}$ 2.072, a qual "[...] deveria enquadrar toda a infância, dos 7 aos 11 anos, e toda a juventude, dos 12 aos 18 anos, no movimento de mobilização cívica nos moldes nacionalista do Estado novo". O Decreto determinava que a organização ficasse sob a vigilância do Presidente da República e que fosse adotado cântico especifico, uniforme e estandarte próprios (STEIN, 2008).

\section{A incorporação da União dos Escoteiros do Brasil à Juventude Brasileira}

Nesse momento histórico, a "cultura escoteira" arraigada em um conjunto de normas que prioriza o civismo, a moral e o aprimoramento físico vai ser uma "aliada" do governo atuando como mais um veículo doutrinador para formar indivíduos identificados com os interesses nacionais.

Em 1940, o presidente Getúlio Vargas incorpora a União dos Escoteiros do Brasil (UEB) à Organização da Juventude Brasileira. Nascimento (2008) assevera que, por ser um movimento que atraía a juventude, o escotismo despertou o interesse de ditadores como Vargas, que se apropriaram da instituição para fortalecer seu projeto político, militarizando a infância e a juventude, a exemplo da Alemanha, Itália e Portugal. A União dos Escoteiros do Brasil foi transformada num departamento do Ministério da Educação, e Getúlio Vargas se proclamou presidente de honra.

Os pesquisadores Zuquim e Cytrynowicz (2002) argumentam que a concepção de uma juventude disciplinada civicamente, moralmente e fisicamente associada à ideia de uma nação forte, fez com que o Estado Novo adotasse o escotismo como modelo para a juventude brasileira. $\bigcirc$ trecho do discurso do presidente Vargas, proferido, no ano de 1939, exalta o modelo de educação escoteira:

Conheço os milagres operados pelo Escotismo em outros países, formando-thes gerações admiravelmente preparadas para todas as eventualidades, quer as da vida civil, quer as da vida militar, e 
espero que o vosso exemplo se espalhe e frutifique, dando ao Brasil inteiro a segurança de que os moços de hoje saberão transmitir, íntegra e honrada, às gerações futuras, a grande Pátria construída pelos seus maiores (DESPERTANDO AS ENERGIAS CÍVICAS DA JUVENTUDE BRASILEIRA, 1939, p. 321.

Uma reportagem publicada no Jornal A República, circulante na cidade do Natal, à época, ratifica o discurso propagado pelas autoridades políticas do Estado Novo:

escoteiro é um elemento dos mais úteis a sociedade, não somente pelos serviços que thes presta abnegadamente e sem alardes, mas, sobretudo, pela rígida obediência da sua disciplina moral e cívica. O código do escoteiro é belo pelos seus princípios morais, humanitários e patrióticos e é dentro de suas normas que se formam escoteiros capazes de honrar e dignificar a nacionalidade. Estado Novo aproveitando todas as organizações verdadeiramente úteis a nação, não poderia deixar de imprimir ao Movimento Escoteiro o grande auxilio moral e material de apoio eficiente e relevante. Por isso mesmo sob o regime atual o movimento tem encontrado no Brasil as melhores oportunidades para reafirmar a sua vitalidade e demonstrar os benefícios da disciplina e da educação moral e cívica traçada para os seus membros. E felizmente essas oportunidades têm sido aproveitadas da melhor forma, tornando o escotismo uma força admirável da juventude brasileira 10 DIA DOS ESCOTEIROS, 1942, p. 4).

Inculcar nos jovens a obediência, a disciplina, a moral e o civismo para formar cidadãos conscientes e aptos a contribuir para a grandeza da nação era o objetivo perseguido pelo Estado Novo, ou seja, era conveniente ao novo regime formar jovens que não contestassem a ordem política vigente. Para disciplinar o corpo da juventude, o governo vai se apropriar dos ideais de Baden-Powell, utilizando o escotismo, como mais uma estratégia, para ajustar o corpo jovem ao modelo pretendido de disciplina, ordem e aprimoramento moral, pois, como adverte Foucault (1987, p. 1 19), " [... ], a disciplina fabrica, assim, corpos submissos e exercitados, corpos dóceis. A disciplina aumenta as forças do corpo (em termos econômicos de utilidade) e diminui essas mesmas forças (em termos políticos de obediência)".

As considerações teóricas sobre o poder disciplinar, tecidas por Foucault (1987), nos possibilitam pensar o Movimento Escoteiro como um 
espaço de produção de disciplina e controle do corpo. Constitui-se, assim, em um produtor do "homem ideal" necessário à pátria. Diante da constante ameaça das "mulheres-macho" que ocupavam empregos "masculinos", desde a I Guerra Mundial, a prática do escotismo passa a ser um exercício de disciplinar e de normatizar o jovem, desde pequeno, para que este assuma um comportamento de defesa nacional. Nesse sentido, as autoridades políticas do estado varguista perceberam, de imediato, que o discurso do Movimento Escoteiro poderia ser utilizado como um dispositivo disciplinar para normatizar os jovens desde a mais tenra idade.

Segundo Parada (2009), a solenidade de incorporação da União dos Escoteiros do Brasil (UEB) à Organização da Juventude Brasileira ocorreu durante a Cerimônia da Hora da Independência, realizada na cidade do Rio de Janeiro, onde 1.000 escoteiros, representando a UEB, fizeram o juramento de incorporação à nova organização. A partir de então, o Movimento Escoteiro, em todo o país, passa a adotar o estandarte e o cântico da Organização da Juventude Brasileira até o final do Estado Novo.

Nascimento (2008) argumenta que, na prática, durante o período de 1937-1945, a UEB, autoridade máxima do escotismo no Brasil, funcionou sob intervenção militar. Somente no ano de 1946, é que um decreto federal reconhece a autonomia dela em relação ao Estado. Em discurso proferido a quatro mil escoteiros, presentes no Encontro Regional de Escoteiros (AJURI) realizado na Quinta da Boa Vista, no Rio de Janeiro, no ano de 1939, Vargas "convoca" os escoteiros a participar da nova organização:

[...] a vossa experiência e treinamento constituirão valiosa e decisiva contribuição para pôr em marcha, vitoriosamente, esse empolgante movimento cívico. Podereis assim mostrar que o Brasil está sempre presente na vossa existência de escoteiros que aos seus serviços destinais o vigor dos músculos adquiridos na ginástica e suas prolongadas marchas, que a sua elevação moral consagrais o aperfeiçoamento do caráter, apurando os vossos ensinamentos dos mestres e da vontade de ser úteis [...] sois a sentinela da pátria que unidos e vigilantes vos constituis os seus defensores em qualquer território, decididos a protegê-la contra tudo e contra todos ICOMO $\bigcirc$ CHEFE DA NAÇÃO FALOU AOS ESCOTEIROS DO BRASIL, 1939, p. 1). 
Na cidade do Natal, o diretor da A.E.A, professor Luiz Soares, recebeu a confirmação da incorporação através de um telegrama enviado pelo presidente da UEB, Heitor Borges, em 27 de julho de 1940. Entretanto, de acordo com a edição do Jornal A República de 18 de janeiro de 1938, o próprio professor Luiz Soares, ao saber que o general Meira de Vasconcelos, comandante da Primeira Região Militar, estava elaborando um projeto educativo para congregar a juventude, solicita a este, que incorpore o escotismo nessa organização:

professor Luiz Soares, diretor da Associação dos Escoteiros do Alecrim, desta capital, sentindo o bem que viria fazer a essa nova organização, os princípios do escotismo, dirigiu a Excia. (sic) um ofício sob o número 385, datado de 26 de agosto último no qual fez um apelo ao ilustre general Meira Vasconcelos, cujos sentimentos de civismo é por todos conhecido, pedindo incluir na organização da Juventude Brasileira o escotismo, cujo código representa uma força moral na educação da juventude (ORGANIZAÇÃO DA JUVENTUDE BRASILEIRA, 1938, p. 2).

De acordo com Parada (2009), após o arquivamento do projeto de Francisco Campos, surgiram vários projetos, principalmente nos meios militares. Horta (2012) explica que o escotismo apareceu como alternativa no momento em que a ideia de se criar um movimento nacional para a juventude começou a ganhar força. No meio militar, alguns oficiais viam o escotismo como forma de ampliar a área de influência do Exército e também como um tipo de preparação para o serviço militar. Já para Nascimento (2008), o Exército pretendia, através do escotismo, ampliar a sua influência sobre as crianças e jovens.

Entusiasmado com o escotismo e com a ideia de criar uma organização para a juventude, o general Meira de Vasconcelos, encaminha para o Presidente da República um projeto, propondo a criação de uma instituição nacional permanentemente encarregada da educação cívica da juventude, utilizando, para esse fim, a doutrina de Baden-Powell (HORTA, 2012).

Stein (2008) argumenta que, ao delegar a educação da juventude ao Exército, o general Meira de Vasconcellos evidencia a sua intenção de militarizar a organização, defender a nação e criar um corpo militar de elite. Mas, para Horta (2012), a proposta do general Meira de Vasconcelos não tinha por objetivo a militarização precoce da juventude e nem o intuito de transformá-la 
em uma milícia armada e organizada. $\bigcirc$ interesse, antes de tudo, era a criação de uma instituição que viesse a garantir uma maior influência do Exército sobre os jovens e que, ao mesmo tempo, proporcionasse uma preparação física, moral e cívica, facilitando, assim, o trabalho de militarização a ser realizado durante o serviço militar.

Provavelmente, o professor Luiz Soares assim como outros dirigentes do escotismo em todo país, temia que a prática escoteira fosse extinta no Brasil, visto que, de acordo com Horta (2012), o primeiro projeto de uma Organização Nacional da Juventude, elaborado por Francisco Campos, vedava, a partir da sua instalação, o funcionamento de quaisquer "formações ou arregimentações" destinadas à educação física, moral e cívica dos jovens:

A década de 1940 teve início com uma grande expectativa do escotismo brasileiro em decorrência da sua incorporação à Juventude Brasileira e determinada em decreto de 14 de julho de 1940. [...] Em 7 de setembro, com a participação de 40 mil estudantes, no estádio do Vasco da Gama, ocorreu a incorporação simbólica do Escotismo àquela organização governamental. Graças à pronta atuação da UEB, a ameaça foi neutralizada ICENTRO CULTURAL DO MOVIMENTO ESCOTEIRO, 2004, p. 1).

Logo após a criação da Juventude Brasileira, ainda no mês de março de 1940, o general Heitor Borges, então presidente da União dos Escoteiros do Brasil, envia um documento ao Ministro da Educação, no qual propõe que seja confiada à instituição por ele presidida, a regulamentação e a execução do Decreto-Lei de criação da Juventude Brasileira. No mesmo documento, o general oferece ainda uma alternativa, caso a sua proposta não fosse viável: o Movimento Escoteiro passaria a integrar a Organização e os grupos de escoteiros seriam considerados "centros cívicos", ficando-lhes assegurado o direito de utilizar os seus próprios métodos para ministrar a educação física, moral e cívica. Ademais, solicitava que os jovens inscritos no Movimento Escoteiro fossem dispensados da obrigação de participar das atividades dos centros da Juventude Brasileira. Em contrapartida, os estatutos da União dos Escoteiros do Brasil teriam que ser aprovados pelo Conselho Supremo da juventude Brasileira. A segunda proposta foi aceita pelo Ministro da Educação e a UEB foi autorizada a manter a sua própria organização (HORTA, 20 12 ). 
Em outras palavras, para que não fosse extinta a União dos Escoteiros do Brasil, apesar de manter a sua personalidade jurídica, teve que se filiar a Organização da Juventude Brasileira e se adequar aos seus princípios:

Para continuar funcionando, a União dos Escoteiros do Brasil estaria, em cada Estado, subordinada ao departamento estadual, que seria responsável pela nomeação de um representante, com a finalidade de moldá-la conforme os princípios da Organização Nacional da Juventude. Além disso, todos os escoteiros brasileiros estariam filiados automaticamente à organização (NASCIMENTO, 2008, p. 3051.

Não podemos esquecer que o professor Luiz Soares era um educador muito atuante no estado norte-rio-grandense. Como presidente da Associação de Escoteiros do Alecrim e diretor do Grupo Escolar "Frei Miguelinho", o professor Luiz Soares dialogava com os ideais educacionais da época, que articulavam disciplina, moral e civismo. Grande entusiasta do escotismo, ele acreditava que o movimento educacional idealizado por Baden-Powell, possibilitaria "[...] o aperfeiçoamento da mocidade pelos meios de estímulo ao seu patriotismo" (SOBRE O ESCOTISMO, 1937, p. 2). Sua confiança nos benefícios que o escotismo proporcionaria para a educação da mocidade, somados ao temor de que o Movimento Escoteiro fosse extinto no país, justifica o pedido do educador potiguar ao general Meira de Vasconcelos.

Em todo o país, o escotismo foi utilizado pelas autoridades políticas como mais uma estratégia para inculcar a ideia de formação do cidadão nacional: viril, forte, saudável, disciplinado e patriótico, ou seja, o escotismo foi utilizado para adestrar a infância, adequando o corpo do brasileiro, desde a mais tenra idade, à ordem política do Estado Novo (BURITI, 2002), configurando mais uma instituição formadora de ideais e práticas cívico-nacionalistas. Nascimento (2008) assevera que tanto a Juventude Brasileira quanto o escotismo estavam inseridos em um contexto fortemente nacionalista e buscavam promover uma educação voltada para a valorização do civismo, do patriotismo, da devoção e fidelidade ao interesse público.

Não obstante, o Estado Novo fez um investimento no "corpo" das crianças e jovens, adestrando-os, manipulando-os e moldando-os através de um processo disciplinar para produzir um corpo educado, obediente e disciplinado, ajustado ao novo regime. 


\section{Aproximações entre Estado Novo e as práticas educativas escoteiras}

Chama-nos a atenção o fato de o escotismo ter sido introduzido no Estado do Rio Grande do Norte por iniciativa, sobretudo de educadores, diferentemente de outros estados brasileiros, onde a iniciativa teria partido de militares. Então, o que explica o interesse desses educadores potiguares pelo escotismo? Ora, a educação, nesse período, primava por uma formação física, cívica e moral do indivíduo, associada à ideia de uma nação forte, justamente os valores que eram difundidos pelo escotismo.

Desse modo, a prática educativa escoteira vinha ao encontro dos interesses educacionais do Estado Novo, haja vista que a pedagogia escoteira se alicerça nos valores morais e cívicos, nos exercícios físicos e no aprender fazendo. Assim, na cidade de Natal, a A.E.A, reconhecida de utilidade pública no estado norte-rio-grandense, pela Lei Estadual n 491, de $1^{\circ}$ de dezembro de 1920, cumpria a função de preparar a juventude dentro de uma educação patriótica": "entre nós, mais profícua não poderia ser a campanha escoteira em prol da educação cívica da mocidade potiguar" (SOBRE O ESCOTISMO, 166 1937, p. 21.

Ressaltamos, também, que a A.E.A foi presidida pelo professor Luiz Soares, desde a sua fundação em 1919 até o ano de 1967, quando o educador faleceu. Isso explica a estreita ligação entre a prática educativa escoteira e a educação "regular" na cidade do Natal. Essa ligação fica ainda mais evidente durante os anos de 1937-1945, recorte cronológico privilegiado nessa pesquisa. Não obstante, a análise das fontes revelou que era recorrente a participação de escoteiros em solenidades do Grupo Escolar "Frei Miguelinho" e em outros Grupos Escolares. Parece-nos que o professor Luiz Soares não conseguia fazer uma separação entre as atividades que desempenhava como diretor do referido Grupo Escolar e as atividades exercidas como presidente da A.E.A., o que sugere que ambas as atividades se complementavam.

Pinto e Morais (2011) argumentam que a preocupação do professor Luiz Soares não se restringia a ensinar o abc, mas também se preocupava com os conhecimentos que se relacionavam à moral, ao caráter e à dignidade. Souza (2013) ressalta que, em 1937, Natal era uma cidade de pequenas proporções, com uma população estimada em 47.000 habitantes, onde o índice de analfabetismo era bastante expressivo, visto que cerca de $80 \%$ da 
população era analfabeta; além disso, aproximadamente, 90\% das crianças em idade escolar estavam fora da escola.

Entendemos que, nesse contexto, a A.E.A vai acenar como possibilidade de educação para as crianças e jovens, principalmente para aquelas das classes menos abastadas, já que as atividades da Associação não se restringiam às atividades escoteiras. A A.E.A era caracterizada como uma "escola de disciplina e ordem" (SOBRE O ESCOTISMO, 1937, p. 2), um espaço escolar que oferecia, também, uma educação profissional:

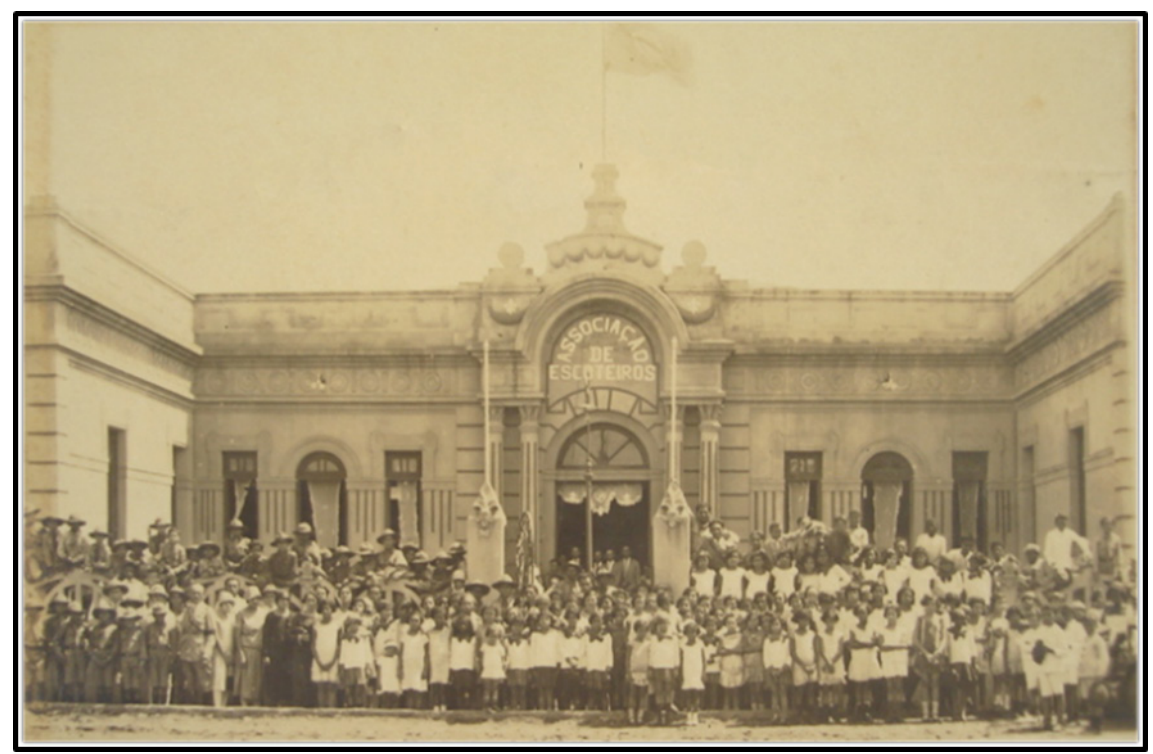

Frente do prédio da Associação dos escoteiros do Alecrim

Fonte | Acervo do Museu do Escoteiro do Rio Grande do Norte (s/d).

Analisando a imagem, percebemos que as instalações da A.E.A apresentavam dimensões generosas, bastante espaçosas, sugerindo que, ali, os escoteiros poderiam desenvolver, de forma confortável, as suas atividades educativas. Além dos escoteiros, estão presentes os alunos do Grupo Escolar "Frei Miguelinho", reforçando assim, a ideia de que as atividades da Associação e do Grupo Escolar estavam imbricadas.

A A.E.A tinha dentro de suas dependências uma escola profissional, denominada Escola Profissional do Alecrim, com oficinas de sapataria, marcenaria, funilaria e mecânica para que seus membros aprendessem um oficio 
Associação dos Escoteiros do Alecrim: uma "escola de disciplina e ordem" para a juventude natalense

(ASSOCIAÇÃO DOS ESCOTEIROS DO ALECRIM, 1937). Ressaltamos que a "Escola Profissional do Alecrim tinha um público específico a atingir, ou seja, apenas os alunos oriundos do Grupo Escolar Padre Miguelinho e os Escoteiros do Alecrim" (SIIVA, 2012, p. 71). A existência de uma escola profissional dento da A.E.A confirma as aproximações desta com os interesses educacionais da época, pois, conforme ressalta Horta (2012), assegurar o ensino profissional às "classes menos favorecidas" era uma das orientações do processo educativo do Estado Novo. Isso fica explicitado no artigo 129 da Constituição de 1937:

O ensino pré-vocacional e profissional destinado às classes menos favorecidas é, em matéria de educação, o primeiro dever do estado. Cumpre-the dar execução a esse dever, fundando instituto ensino profissional e subsidiando os de iniciativa dos Estados, dos Municípios e dos indivíduos ou associações particulares e profissionais (CONSTITUICCÃO DOS ESTADOS UNIDOS DO BRASIL, 1937, p. 33).

A industrialização em curso no país demandava a formação profissional. Assim, a A.E.A, além de ministrar uma educação pautada nos valores cívicos e morais do método de Baden Powell, também oferecia uma educação profissional, constituindo-se em um espaço educativo relevante para a formação dos jovens natalenses.

Havia ainda, dentro de suas dependências, um cinema educativo, o primeiro a ser instalado no Nordeste, que exibia filmes educativos três vezes por semana, provavelmente, filmes que exaltavam a nacionalidade e o patriotismo. Bercito (1990, p. 54) destaca que "[...] enfatizar a educação cívica e nacionalista era a principal orientação da política educacional. Objetivava-se formar indivíduos identificados com os interesses nacionais', integrados na tarefa de fazer do Brasil uma grande nação [...]", ou seja, a educação no período varguista tem por objetivo a produção do "novo homem brasileiro", adequado a essa "nova sociedade" que estava sendo formada, conforme explicita Capellato:

As imagens e os símbolos eram difundidos nas escolas com o objetivo de formar a consciência do pequeno cidadão. Nas representações do Estado Novo, a ênfase no novo era constante: o novo regime prometia criar o homem novo, a sociedade nova e 
o país novo. $\bigcirc$ contraste entre o antes e o depois era marcante: o antes era representado pela negatividade total e o depois (Estado Novo) era a expressão do bem e do bom (CAPELLATO, 2010, p. 123).

Segundo Parada (2009), a educação cumpria a função de divulgar o novo regime. Para isso, os jovens escolares foram mobilizados e envolvidos no projeto político que dava sustentação ao Estado Novo. Uma das tecnologias de poder, utilizada para essa mobilização, foram as cerimônias cívicas que exerceram um papel decisivo na construção de uma cultura política, ancorada em um projeto de nacionalidade, em que as representações de nação e infância se relacionavam. Um calendário de cerimônias cívicas, articulando as ideias de ordem, solidariedade, disciplina, saúde e modernidade, foi elaborado nos primeiros anos do Estado Novo. Nesse sentido, o sete de setembro foi transformado em Semana da Pátria e institui-se o Dia da Bandeira e o Aniversário do Estado Novo, acrescenta-se ainda A Hora da Independência e o Dia da Juventude ${ }^{8}$.

autor argumenta que o Estado Novo utilizou o calendário cívico para se "inventar" e se legitimar. Esses desfiles ocorriam em todo o país e, além dos jovens escolares, matriculados no ensino público e privado, mobilizavam os militares, os trabalhadores e também os escoteiros, todos eram "convidados" a participar. Na cidade do Natal, esses eventos cívicos eram amplamente divulgados pela imprensa local:

O dia 19, consagrado ao Dia da Bandeira, terá neste Estado uma comemoração à altura do acontecimento que naquele dia fará vibrar todos os brasileiros que amam verdadeiramente a pátria. Desde agora convidamos o povo a festejar a data com toda a vibração patriótica. A cidade deverá homenagear o nosso pavithão, dando um exemplo de fé nos destinos do nosso querido Brasil. Hoje mais do nunca para a defesa da terra comum. Espera assim - governo que no dia 19 seja hasteada a bandeira brasileira em todos os recantos da cidade (O DIA DA BANDEIRA, 1939, p. 7).

Esses eventos eram organizados com antecedência para que tudo ocorresse conforme havia sido planejado. Era um acontecimento na cidade, que mobilizava grande parte da população, pois os que não desfilavam iam para as ruas para prestigiar o desfile. Os escoteiros da A.E.A, exemplo de 
Associação dos Escoteiros do Alecrim: uma "escola de disciplina e ordem" para a juventude natalense

civismo, eram presenças confirmadas nesses eventos, junto a sua banda de música, pois, conforme assevera Parada (2009), eram, nas cerimônias cívicas, que se encenavam os valores cívicos pretendidos pelo regime varguista.

\section{Considerações finais}

Associada diretamente à manutenção da ordem e à continuidade do regime político do Estado Novo, a juventude estava no centro dos debates políticos e dos projetos educacionais. Dessa forma, as práticas educativas escoteiras da Associação de Escoteiros do Alecrim não se constituíram em uma agência isolada para treinar jovens, mas estabeleceram uma série de diálogos com os ideais político-pedagógicos do Estado Novo.

Com esse objetivo, no ano de 1940, foi organizada a Juventude Brasileira, que mobilizou a infância dos 7 aos 11 anos e a juventude dos 12 aos 18 anos, em um movimento de educação cívica. Para facilitar a disciplinarização do corpo juvenil, as autoridades políticas do Estado Novo se apropriaram do escotismo e incorporaram, ainda em 1940, a União dos Escoteiros do Brasil à Juventude Brasileira. A partir de então, todo o Movimento 170 Escoteiro ficava sob a tutela do Estado.

Ao discutirmos essa problemática sob inspiração dos pressupostos teóricos de Michel Foucault (1987), e de Dominique Julia (2001), concluímos que, nesse período, as autoridades políticas do Estado Novo se apropriaram da prática educativa escoteira, incorporando a União dos Escoteiros do Brasil (UEB) à Organização da Juventude Brasileira, com a finalidade de treinar jovens para a pátria. A partir de então, a Associação de Escoteiros do Alecrim passou a educar e normatizar o comportamento da juventude natalense, adequando-a aos moldes do regime vigente. A Associação de Escoteiros do Alecrim, pelo desenvolvimento de suas práticas escoteiras (alicerçadas na obediência, disciplina e na valorização do civismol passou a dialogar com os ideais político-pedagógicos, pretendidos pelo Estado Novo naquele momento.

Constatamos, ainda, que a A.E.A não se limitava aos ensinamentos de Baden-Powell. Presidida pelo professor Luiz Soares, a A.E.A mantinha, em suas dependências, a Escola Profissional do Alecrim, que disponibilizava oficinas de marcenaria, sapataria entre outras, para que os seus membros pudessem aprender uma profissão, coadunando, assim, com a orientação do ensino profissional em voga nesse período. Além da escola profissional, 
disponibilizava, também, um cinema educativo para exibição de filmes que, provavelmente, exaltavam a nação e os valores cívicos e morais, contribuindo para a perpetuação de uma cultura escolar aos moldes do regime do Estado Novo. Mantinha, ainda, uma banda de música que se fazia presente nas solenidades que ocorriam na cidade, principalmente nos eventos cívicos que legitimavam e exaltavam o regime estadonovista.

Entendida, neste estudo, como espaço disciplinar, a A.E.A configurou uma "[...] escola de civismo altamente influente na constituição moral da mocidade" (SOBRE O ESCOTISMO, 1941, p. 10), educando e normatizando os comportamentos dos jovens natalenses, adequando-os aos ideais político-pedagógicos do Estado Novo. Considerando que a Associação dos Escoteiros do Alecrim é parte da memória educacional do Estado do Rio Grande do Norte, esta pesquisa é uma contribuição à historiografia da educação no Brasil, bem como visa provocar o debate e a produção acadêmica sobre a prática escoteira em outros estados da federação.

\section{Notas}

1 Já no ano de 1908, são organizados grupos de escoteiros no Canadá, Austrália, Noruega e Nova Zelândia e em 1910, é implantado o escotismo na Índia, Argentina, Chile, Noruega, Suécia, Estados Unidos e Brasil (NAGY, 1987).

2 O Grupo Escolar "Frei Miguelinho" foi criado pelo Decreto n 277 - B, de 28 de novembro de 1912, no bairro de Alecrim - Natal/Rio Grande do Norte; era constituído por três escolas, sendo duas elementares. Inaugurado no dia 21 de abril de 1913, funcionou até 1962, quando seu prédio foi demolido para ceder lugar ao prédio hoje existente. Foi reinaugurado em 31 de janeiro de 1963. Com a Lei n².880, de 21 de abril de 1963 o então Grupo Escolar passou a denominar-se Instituto Padre Miguelinho.

3 Luiz Soares Correia de Araújo, conhecido como professor Luiz Soares, dirigiu o Grupo Escolar Frei Miguelinho desde a sua fundação, no ano de 1913, até o ano de 1967.

4 Antônio José de Melo e Souza governou o Estado do Rio Grande do Norte entre os anos de 1921-1924.

5 Epitácio Pessoa foi presidente da República entre os anos de 1919-1922.

6 Joaquim Ferreira Chaves foi governador do Estado do Rio Grande do Norte por duas vezes: o primeiro mandato foi de 1896-1900, já o segundo mandato foi entre os anos de 1914-1920.

7 O Decreto $n^{\circ} 2.176$, de 13 de dezembro de 1937 e o Decreto n 3.288, de 22 de novembro de 1938 assinados por Getúlio Vargas e publicados no Diário Oficial confirmam o auxílio a A.E.A nesse período.

8 Dia da Juventude, instituído pelo Ministério da Educação e Cultura, no ano de 1936, foi inicialmente chamado de Dia da Raça e da Mocidade (PARADA, 2009). 


\section{Referências}

ARAÚjO, Maria Celina. O Estado Novo. Rio de Janeiro: Zahar, 2000.

ASSOCIAÇÃO DOS ESCOTEIROS DO ALECRIM. A República, Natal, 13 mar. 1937, p. 1 .

BERCITO, Sônia de Deus Rodrigues. Nos tempos de Getúlio: da revolução de 30 ao fim do Estado Novo. São Paulo: Atual, 1990.

BLOWER, Almirante Bernard David. História do escotismo brasileiro: os primórdios do escotismo no Brasil. Rio de Janeiro: CCME, 1994.

BRASIL. Constituição dos Estados Unidos do Brasil ( 10 de novembro de 1937). Disponível em: <file:///D:/Filmes/constituicao_1937_texto.pdf> Acesso em: 12 mar. 2016.

BRASIL. Decreto $\mathbf{n}^{\circ}$ 2.176, de 13 de dezembro de 1937. Disponível em: < hitp:// www2.camara.leg.br/legin/fed/decret/1930-1939/decreto-2176-13-dezembro-1937-346476-publicacaooriginal-1-pe.html>. Acesso em: 4 abr. 2017.

BRASIL. Decreto-Lei $\mathbf{n}^{\circ} \mathbf{3 . 2 8 8}$, de 22 de novembro de 1938. Disponível em: <http:// www2.camara.leg.br/legin/fed/decret/1930-1939/decreto-3288-22-novembro-1938-348242-publicacaooriginal-1-pe.html>. Acesso em: 4 abr. 2017.

BRASIL. Decreto-Lei $\mathbf{n}^{\circ}$ 2.072, de 8 de Março de 1940. Disponível em: < http:// www2.camara.leg. br/legin/fed/declei/ 1940-1949/decreto-lei-2072-8-marco-1940-412103-publicacaooriginal-1-pe.html>. Acesso em: 4 abr. 2017.

BURITI, Iranilson. Façamos a família à nossa imagem: a construção de conceitos de família no Recife moderno (décadas de 20 e 30). 2002, 348f. Tese (Doutorado em História) Programa de Pós-Graduação de História. Universidade Federal de Pernambuco, Recife, 2002.

CAPELATO, Maria Helena. O Estado Novo: o que trouxe de novo? In: FERREIRA, Jorge; DELGADO, Lucilia de Almeida das Neves. O tempo do nacionalestatismo: do início da década de 1930 ao apogeu do Estado Novo. 3. ed. Rio de Janeiro: Civilização Brasileira, 2010.

CARVALHO, José Murilo de. A formação das almas. $\bigcirc$ imaginário da República no Brasil. São Paulo: Companhia das Letras, 1990.

CENTRO CULTURAL de Memória Escoteira. Memória Escoteira, Rio de Janeiro, v. 1 1, n. 50, maio/set. 2004.

COMO $\bigcirc$ CHEFE da nação falou aos escoteiros do Brasil. A República, Natal, 21 jun. 1939, p. 1. 
DAYRELL, Juarez. $\bigcirc$ jovem como sujeito social. Revista Brasileira de Educação, Rio de Janeiro, v. 5/6, n. 24, p. 40-52, 2003.

DESPERTANDO AS ENERGIAS cívicas da juventude brasileira. Revista Carioca, Rio de Janeiro, n. 192, p. 32-33, 1939. Disponível em: <http://chamaescoteira.wordpress. com/tag/1939/> Acesso em: 12 mar. 2016.

ESCOTEIROS COMEMORAM 51 anos de existência. Diário de Natal, Natal, 14 jul. 1970, p. 2.

ESCOTISMO NO RN completa 90 anos. Disponível em: <http://tribunadonorte.com.br/ noticia/escotismo-no-rn-completa-90-anos/441 12>. Acesso em: 5 mar. 2016.

FOUCAULT, Michel. Vigiar e punir: nascimento da prisão. Tradução Lígia Maria Pondé Vassalo. Petrópolis: Vozes, 1987.

GROPPO, Luis Antonio. Dialética das juventudes modernas e contemporâneas. Revista de Educação do COGEIME, São Paulo, v. 13, n. 25, dez. 2004.

HORTA, José Silvério Baia. $O$ hino, o sermão e a ordem do dia: regime autoritário e a educação no Brasil (1930-1945). 2. ed. rev. Campinas: Autores Associados, 2012.

INSTITUTO PADRE MIGUELINHO. Disponível em: https://pt.wikipedia.org/wiki/Instituto_ Padre_Miguelinho. Acesso em: 6 mar. 2016

JÚllA, Dominique. A cultura escolar como objeto histórico. Revista Brasileira de História da

Educação, Campinas, n. 1, p. 9-44, jan./jul. 2011

LUCA, Tânia Regina de. História dos, nos e por meio dos periódicos In: PINSKY, Carla Bressanezi (Org.). Fontes Históricas. São Paulo: Contexto, 2008.

NAGY, Laszlo. 250 milhões de Escoteiros. Porto Alegre: União dos Escoteiros do Brasil, 1987.

NASCIMENTO. Adalson de Oliveira. Sempre alerta! O Movimento Escoteiro no Brasil e os projetos nacionalistas de educação infanto-juvenil (1910-1945). 2004, 173f. Dissertação (Mestrado em História) - Programa de pós-graduação em História, Universidade Federal de Minas Gerais, Belo Horizonte, 2004.

NASCIMENTO, Jorge carvalho do. A escola de Baden-Powell - cultura escoteira, associação voluntária e escotismo de estado no Brasil. Rio de Janeiro: Imago, 2008.

ORGANIZAÇÃO DA JUVENTUDE Brasileira. A República, Natal, 18 jan. 1938, p. 2.

O DIA DA BANDEIRA. A República, Natal, 13 nov. 1939, p. 7.

O DIA DOS ESCOTEIROS. A República, Natal, 23 abr. 1942, p. 4. 
O ESCOTISMO. Diário de Pernambuco, Recife, 1 abr. 1936, p. 3 (secção Gury).

O PAPEL DA JUVENTUDE no Estado Novo. A República, Natal, 22 jun. 1938, p. 10.

PARADA, Maurício. Educando corpos e criando a nação: cerimônias cívicas e práticas disciplinares no Estado Novo. Rio de Janeiro: Editora PUC-Rio/ Apicuri, 2009.

PINTO, Amanda Thaíse Emerenciano; MORAIS, Maria Arisnete Câmara de. História e prática pedagógica do Grupo Escolar "Frei Miguelinho" Natal/RN (1912-1920). In: CONGRESSO BRASILEIRO DE HISTÓRIA DA EDUCAÇÃO, 6., 2011 , Vitória. Anais.. Vitória: SBHE, 2011.

RIO GRANDE DO Norte. Lei n 491, de $1^{\circ}$ de dezembro de 1920. In: Sobre o Escotismo. A República, Natal, 23 abr. 1937, p. 2.

RIO GRANDE DO Norte. Decreto n²77- B, de 28 de novembro de 1912. Cria o Grupo Escolar Frei Miguelinho. Atos legislativos e decretos do Governo de 1909. A República, Natal, RN, $1912 e$.

SILVA, Maria da Guia de Souza. Escola para os filhos dos outros: trajetória histórica da Escola Industrial de Natal (1942-1968). 2012, p. 224f. Tese (Doutorado em Educação) Programa de Pós-Graduação em Educação. Universidade Federal do Rio Grande do Norte. Natal, 2012.

174 SOBRE O ESCOTISMO. A República, Natal, 23 abr. 1937, p. 2.

SOBRE O ESCOTISMO. A República, Natal, 27 nov. 1941, p. 10.

SOUSA, Francisco Carlos Oliveira de. Estado Novo: novas práticas? - A educação escolar no Liceu Industrial Rio Grande do Norte (1937-1942). In: SIMPÓSIO NACIONAL DE HISTÓRIA-CONHECIMENTO HISTÓRICO E DIÁLOGO SOCIAL, 27; 2003. Natal. Anais... Natal: Universidade Federal do Rio Grande do Norte, 2013.

SOUZA, Rosa Fátima de. A militarização da infância: expressões do nacionalismo na cultura brasileira. Cadernos CEDES, Campinas, v. 19, n. 52, p. 109-1 10, nov. 2000,

STEIN, Cristiane Antunes. Por Deus e pelo Brasil: a Juventude Brasileira em Curitiba (19381945). 2008, 169f. Dissertação (Mestrado em Educação) - Programa de Pós-Graduação em educação, Universidade Federal do Paraná, Curitiba, 2008.

TEIXEIRA, Clara. Cinejornal Brasileiro: eugenia adaptada no Estado Novo. Revista Científica, Curitiba, v. 8, p. 163-180, jul./dez. 2011.

ZUQUIM, Judith; CYTRYNOWICZ, Roney. Notas para uma história do escotismo no Brasil: a "psicologia escoteira" e a teoria do caráter como pedagogia do civismo (1914- 1937).

Educação em Revista, Belo Horizonte, n. 35, p. 43-58, jul. 2002. 
Prof. Dr. Iranilson Buriti de Oliveira Universidade Federal de Campina Grande Unidade Acadêmica de História Programa de Pós-Graduação em História | Universidade Federal de Campina Grande Programa de Pós-Graduação Educação | Universidade Federal da Paraíba | João Pessoa Grupo de Estudo em História das Práticas e Discursos Médicos Bolsista produtividade do CNPq E-mail | iburiti@yahoo.com.br

Doutoranda Andressa Barbosa de Farias Leandro Universidade Federal da Paraíba | João Pessoa Programa de Pós-Graduação em Educação Grupo de Pesquisa História das Práticas e Discursos Médicos E-mail | andressa-leandro@hotmail.com Aceito 27 abr. 2017 